\title{
Environmental applications of electrochemical technology. What is needed to enable full-scale applications?
}

\author{
E. Lacasa ${ }^{1}$, S. Cotillas ${ }^{1}$, C. Saez ${ }^{2}$, J. Lobato ${ }^{2}$, \\ P. Cañizares ${ }^{2}$ and M. A. Rodrigo ${ }^{2}$
}

\begin{abstract}
In recent years, thousands of scientific articles have considered the application of electrochemical technologies to remediate environmental problems ranging from the treatment of polluted soils to the removal of hazardous species from industrial liquid wastes. New research topics continue to emerge. Despite such research efforts, the technology readiness level (TRL) for many of those technologies remains very low; although most are considered promising, many are far from being introduced as efficient processes into the market. Important barriers need to be overcome to reach high TRLs. Some of these are scientific or technological and generate the opportunity for critical, applied research. Others are related to the lack of components in the value chain of the technology and generate opportunities for entrepreneurs to benefit from an improvement in the TRL. In this short review, a brief description of the current state of the most relevant technologies which are still in low TRL is carried out, highlighting barriers that must be removed to achieve full-scale applications in industry.
\end{abstract}

\section{Addresses \\ ${ }^{1}$ Chemical Engineering Department, School of Industrial Engineering, University of Castilla-La Mancha, Edificio Infante Don Juan Manuel, Avenida de España S/n, 02071 Albacete, Spain \\ ${ }^{2}$ Chemical Engineering Department, Faculty of Chemical Sciences and Technologies, University of Castilla-La Mancha, Edificio Enrique Costa Novella, Campus Universitario S/n, 13005 Ciudad Real, Spain \\ Corresponding author: Rodrigo, M.A (manuel.rodrigo@uclm.es)}

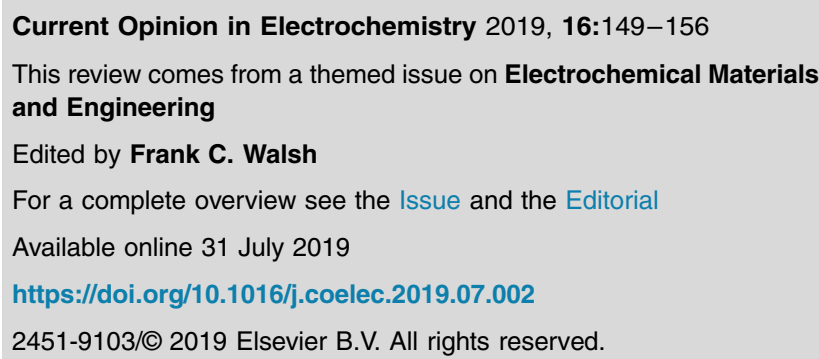

Keywords

Environment, Electrochemical AOPs, Electrodialysis, Electrocoagulation, TRLs.

\section{Introduction}

Applications of electrochemical technology in environmental remediation have been the focus of many research activities over the last three decades [1]. Thousands of publications have sought to develop new technologies or improve existing processes. After this long period, very few technologies are being applied at full scale and most technologies evaluated remain at the status of 'promising' technologies. Most have identifiable benefits, but important technological and cost handicaps can be identified, which are related to missing components in the value chain of the technology.

Electrolytic processes include the cathodic deposition of metals found in the widely used electrowinning and electrorefining processes and the oxidation of organic compounds, either direct on the anode surface or mediated by oxidants produced on the anode or on the cathode surface. This second case is of a great significance because hydrogen peroxide can be efficiently produced from the reduction of oxygen using gas diffusion electrode (GDE) electrodes [2] or more recently using cross-flow electrodes even with the application of high pressures [3], leading to more efficient processes. Electrocoagulation technologies are also initiated by the electrolytic release of coagulants from a sacrifice anode and can be used to break up emulsions in industrial wastes or to remove colloid pollutants in those wastes and during the treatment of surface water [4].

Electrochemically assisted separation processes include not only electrodialysis [5] and capacitive deionisation [6] (which allow concentration of ions in liquids) but also electrokinetic processes (which allow transport of species in solid-liquid mixtures such as soil or sludge) $[7,8]$.

Not all electrochemically assisted processes are at the same technology readiness level (TRL). Large differences are found between electrowinning or electrodialysis and the electrolysis of wastewater polluted with organics. Sometimes, the key to understand these 
differences is a necessity for companies aiming to develop those processes, especially when there is a lack of alternatives. When competitive solutions are fully marketed, it is difficult to displace them, unless the advantages of the new technology would help to obtain a very fast payback. Lessons must be learned about the successful implementation of electrodialysis and electrodeposition of metals, to achieve full applicability of other electrochemical technologies and to allow returns on invested money to companies and society.

Many electrochemical technologies, including the electrochemical oxidation of wastewater, electrodisinfection, electrocoagulation and soil electroremediation, are now in a position to improve TRLs. Sometimes, the challenge to be faced is technical; in other cases, it is economic. The following is a brief critique of each of these.

\section{Challenges in water treatment: electrodisinfection}

While the use of mixed metal oxide anodes has been demonstrated for the disinfection of water, particularly the production of chlorinated disinfectants, a long path remains to push the technology from traditional disinfection of saline swimming pools or spas, in which many small and medium enterprises (SMEs) are focussing their markets [9].

Two important challenges must be faced to meet this challenge. One is to determine how to avoid the formation of hazardous by-products such as chlorates or trihalomethanes. Chlorates are formed by oxidation of hypochlorite or by its disproportionation, which is a natural process that also occurs during ageing of the disinfected water. This species is related to serious health problems because it is known to affect the nervous system. The second type of hazardous species is even more controversial. Chlorinated organics are formed from the combination of organic matter with active species of chlorine, and these species are related to cancer and other very serious illnesses. These species are not characteristic of the electrochemical process, because they are also formed during the application of conventional chlorination technology. The other challenge is to apply replacements for mixed metal oxide anodes, such as diamond-like coatings, capable of not only oxidising chloride ions but also producing more efficient disinfectants, including hydroxyl radicals. When using these electrodes, problems associated with the production of hazardous species can be aggravated, because of the well-known production of perchlorates via oxidation of chlorates. These new electrode materials open the possibility of promoting the action of other oxidising reagents, for example, ozone and peroxosalts, [10] to help remove resistant pathogens. An adequate contact time between water and the anodes in the electrolyser, a sufficiently large specific current and the cathodic formation of hydrogen peroxide to prevent further oxidation of chlorine to chlorates and perchlorates are among strategies considered to overcome problems [11]. In this way, $\mathrm{R}$ \& $\mathrm{D}$ departments in many companies are making efforts not only to develop new electrodes but also to design electrochemical cells that avoid the formation of undesirable products and offer improved volumetric electrode area, mass transfer and current efficiency. Important projects include the SafeWaterAfrica European Union (EU) programme, in which two full-scale demonstrators based on this technology are being commissioned to treat water in rural communities in South Africa and Mozambique, and they are expecting to be in operation during 2019 [12].

\section{Challenges enabling electrocoagulation to compete with coagulation}

Electrocoagulation is an alternative to conventional coagulation, in which the coagulant is provided by the dissolution of sacrificial electrodes [13]. The simplicity of operation and the side processes involving the production of bubbles are major advantages. In the first case, the dose of coagulant reagent can be adjusted simply by regulating the intensity exerted, and the handing of reagents is avoided. In the second case, a proper mechanical cell design can help to utilise oxygen and hydrogen microbubbles to promote turbulence and enhance the flocculation of particles (so-called electroflocculation). Sometimes, separation can be promoted by flotation, once microbubbles have adhered to the surface of the flocs, diminishing their overall density (in so-called electroflotation). However, authors disagree in this assessment: the main advantage of electrocoagulation, compared with coagulation, is related to the $\mathrm{pH}$ regulation. In conventional coagulation, the reagents consist of salts of iron or aluminium; the main reagent in electrocoagulation is hydroxyl ions, and the counter ion does not increase the salinity of the treated waste. Salts used in coagulation perform as Lewis acids and require neutralisation by alkali additions, to obtain an acceptable $\mathrm{pH}$. This increases the salt load of the treated waste and the volume of sludge, resulting in an effluent with a much higher conductivity. Conversely, the electrocoagulation can self-regulate the $\mathrm{pH}$, and there is no necessity of addition of $\mathrm{pH}$-neutralising reagents $[14,15]$.

Although the laboratory design of an electrocoagulation cell is very simple, its scale-up is not as easy $[13,16]$. It is not always possible to use tank cells with sheets of iron and aluminium, and there is a need to use cheap materials as sacrificial electrodes. Use of low-quality iron or aluminium can enable bipolar electrode configurations to be used. Achieving a low cell voltage is a major challenge, and components of cell voltage are rarely 
quantified. The combination of electrocoagulation with free radical-assisted processes is a promising approach to encourage its implantation at full scale $[17,18]$.

\section{Challenges in the treatment of industrial wastes: removal of refractory pollutants}

One the most exciting research topics in recent years has been the development of technologies for the treatment of industrial wastes in cases where the application of biological technologies and other cheap processes are inefficient. In this field, many technologies have been developed, most of them being classified as advanced oxidation processes (AOPs). The key oxidant involved is the hydroxyl radical. This radical has two great advantages as compared with other traditional oxidants, as in the case of chlorine used in the $70 \mathrm{~s}$ and 80s: the hydroxyl radical minimises formation of hazardous by-products and can be faster and more efficient, because of the harsh oxidation conditions. Despite outstanding developments in this field, reflected in a large bibliography, many challenges remain [19].

Regarding the relationship between these AOPs and electrochemical technology, several features may be noted: (1) the confirmation in 2003 of the active role of hydroxyl radicals in the electrochemical oxidation with diamond electrodes [20] and (2) the introduction of the combination of Fenton and electrochemical technologies $[21,22]$ led to the recognition of a new category of AOP processes, namely electrochemical AOPs [2,2325].

Regarding the current status of this technology, the application of electrochemical AOPs for the removal of many types of organic pollutants (both, from synthetic and real wastewater) has been widely studied. Many authors have tried to elucidate the role of electrochemical cell design and types of electrode on the electrochemical process. It has been stressed that a key requirement in the potential applicability of the electrochemical technology is the efficient use of all the components of the electrochemical cell [26-28]. This implies not only the implementation of a suitable anode but also the synergistic use of the cathode reaction and the promotion of mediated oxidation processes in the bulk during the treatment. In addition, the increase in the mass transfer rate inside the cell is also important. Thus, an efficient mechanical design of the cell and a careful choice of the operation conditions are critical to achieve good performance. Despite these efforts, the technology is still at an intermediate TRL and major developments are needed to reach higher readiness levels which recognise adequate mechanical design of the electrochemical cell to obtain good patterns for flow and current distribution [29], scale-up either by increasing electrode size of by stacking [30], the management of hydrogen generated [31,32] and DC electrical power requirements [33]. Many of these points necessitate collaboration between companies and academia; any slowness at this interface must be considered a major handicap to the implementation of electrochemical technology.

\section{Challenges in soil remediation: not only metals but also organics?}

Application of electric fields to transport water and pollutants in soil has been known for many decades. The possibilities of using this technology to efficiently remove metals from soil or those derived from the transport of volatile and semivolatile pollutants with the heat produced [34] have been described. Both applications are currently at a high TRL, with many companies applying commercial solutions in the first and over TRL 6 in the case of the second.

The focus of research in recent years, however, has been the use of this technology to remove other pollutants, particularly hazardous organics contained in soil [35] or in marine and river sediments [36]. A plethora of technologies has been reported, ranging from simple electrokinetic soil flushing for soils with low hydraulic conductivity [37] to the more complicated use of permeable reactive barriers loaded with granular activated carbon (GAC), zero-valent iron [38] or even microorganisms [39] have been used to retain or transform organics mobilised by applied electric fields. Scale-up is critical; it affects not only the speed of treatment [4042] but also the efficiency and selectivity reported in research studies: there is often poor reproducibility of results obtained on the laboratory scale (where electrokinetic processes are rate controlling) to larger scales (where ohmic and heating effects can dominate). Multidisciplinary aspects range from the compaction of soil to the physical position of electrodes. Further research is needed because technical and environmental concerns will demand careful evaluation before fullscale applications. These include controlling side effects during treatment (such as anodic precipitation, heating of the soil, gas formation), as well as evaluating the potential ecotoxicological effects of the surfactants, cosolvents, oxidants or reductants used [43].

\section{Challenges in the treatment of gaseous streams: a new frontier in environmental applications?}

Treatment of gaseous streams has not been extensively studied using electrochemical technologies, except for studies focused on the valorisation of gaseous streams in high-temperature fuel cells. However, there is a very interesting market niche, not only related to industrial environments but also complementing other treatment technologies in which gaseous effluents are produced [44]. The application of electrochemically assisted 
technologies to remediate soil can lead to significant increases in soil temperature and to release of volatile and semivolatile pollutants that must be treated. The integration of adsorption units with electrochemical cells is the goal and promising results have recently been obtained [45], although further research is needed to scale-up this treatment technology.

Once the pollutant is in the liquid phase, the process becomes easier and similar to wastewater treatment. This means that expertise developed over previous decades can be used. However, some recent studies have pointed out the possibility of using methanol instead of water for collecting more efficiently the organics contained in the gas [46]. This is especially important when electrolysis is combined with adsorption, because methanol is more efficient to regenerated GAC, and results show that combined GAC adsorptiondesorption in methanol and electrolysis of the resulting solution allows to remove completely target pollutants in a more efficient way, requiring much less electrical charge than the electrolysis in aqueous phase. However, the efficiency of the overall removal process not only depends on the performance of the electrochemical process but also depends on the adsorption equilibria of the pollutant in methanol media. In any case, preliminary works allow the confirmation of this combined technology as a real challenge in the treatment of gaseous streams polluted with organics.

\section{Challenges in sanitary effluents: is there slot for electrochemical technology?}

Medical facilities, such as hospitals, produce sanitary effluents with a high load of a great variety of chemicals (e.g., pharmaceuticals, detergents, disinfectants, heavy metals, radionuclides) and pathogens. No legal regulations have been established to define how to manage and treat sanitary effluents, and thus, they are directly discharged in public sewage for treatment at conventional municipal wastewater treatment plants (WWTPs). The inefficiency of biological treatments from WWTPs to treat sanitary effluents leads the spread of chemicals and pathogens in the environmental water sources, negatively affecting aquatic organisms and human health. This has led to proliferation of numerous studies searching for technological solutions to decrease the impact of sanitary effluents in the environment. Two main strategies have been developed: (1) boosting efficient treatments at WWTPs by the application of additional treatment and (2) pretreatment before their discharge into WWTPs [47]. The second option is emerging as the key alternative, as it addresses the problem in more concentrated effluents and the volume of wastewater treated is further much lower than in the other case. Some authors have focussed on the treatment of hospital urines, where both pharmaceuticals and pathogens are more concentrated and an improvement in the process efficiency is expected, as well as lower investment and operational costs. Among the available technologies, a single electrochemical technique such as electrochemical oxidation or electroFenton and the combination of free radical-assisted electrochemical technologies have demonstrated complete disinfection and partial oxidation of chemicals towards the decrease of toxicity and increase of biodegradability of urines and sanitary effluents $[48,49]$.

\section{Challenges in the sustainable powering of electrochemical technology}

Sustainability is currently an overused word. We are far exceeding the capacity of our planet to provide raw materials and energy, and solutions for problems generated should be as much sustainable as possible. Here, it is important to realise that the main requirement of electrochemical processes is electricity and green supply by photovoltaic solar panels or wind turbines has been proven to be efficient to power these devices, especially when the power demand is not so high. This supply can be direct or by means of energy storage devices. In the first cases, there are important differences between the application to water treatment [31] or soil because of the reversibility of the transport processes in soil remediation [50,51] which leads to lose efficiency over nights when photovoltaic (PV) technology is used or when no wind is available to produce electricity. In the second case, the use of redox flow batteries is seeming to be a good alternative because they can store important amounts of energy and help to regulate renewable

Figure 1

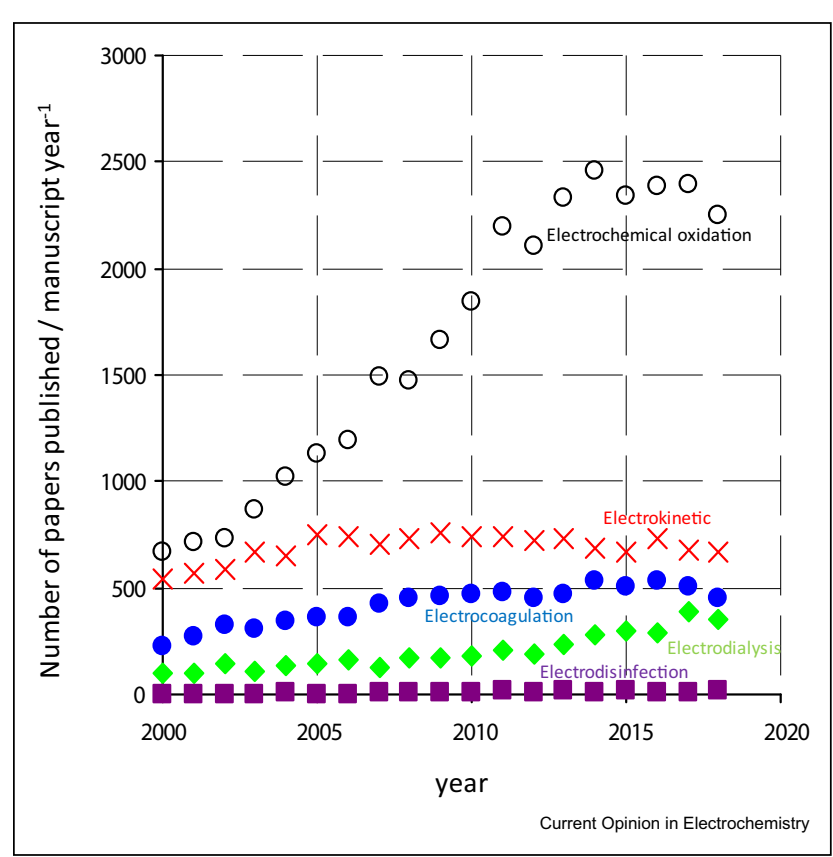

Number of publications per year related to different environmental electrochemical technologies according to Scopus. 
energy in this electrochemical application [52-54]. Despite this topic is being considered useful in the scientific and technical literature, it requires further development in the next few years to reach high TRLs enabling full-scale application.

\section{Concluding remarks: the big challenge - scaling up and commercialisation}

Figure 1 shows a rapid survey carried out with the number of items published per year according to the Scopus since 2000, in the different topics covered in this short review (it is only informative because the keywords are not unique for each technology, and it is not aimed to be an exhaustive evaluation but just a quick outlook that helps the reader to have in mind the bibliometric significance of the research topic), where it can be seen that publications per year related to electrochemical oxidation (keywords used: electrochemical oxidation, electro-fenton, electrofenton, anodic oxidation and electrooxidation) have increased significantly, although they are stabilised in the last five years, suggesting some sort of exhaustion of the new ideas in the topic. In comparing the different technologies, it can be drawn that this high number of publications from electrochemical AOPs is more important than that of the publications related to electrokinetic soil remediation. In turn, these publications remain more important than the number related to electrocoagulation and electrodialysis. It is also interesting to see that the rate of publication is almost constant in all technologies except for electrodialysis in which a slight increase is observed over recent years. All these data indicate the relevance of the research in environmental electrochemical technologies.

As explained in this work, bibliometric comparison is not the focus here. Rather, real world applicability of the technologies is critical. Although the original idea dates back to the early $70 \mathrm{~s}$, it is at the end of the $80 \mathrm{~s}$ when NASA defined the nine-level TRL scale, which later was adopted by the EU in the mid-2000s to be used in its research framework program H2020. From the initial steps in the research (TRL1: basic principles observed) to the final (TRL9: actual system proven in operational environment), different goals and actors must perform to reach the market from fundamental research. Figure 2 shows what can be considered as the most advanced applications of the environmental electrochemical technology, the approximate TRL reached currently and barriers that are limiting the improvement in the TRL. In some cases, nonenvironmental electrochemical technologies have been also included for the sake of comparison (electrowinning and electrorefining data are provided to point out the differences between the industrial and the environmental processes and purification of acids and alkalis with electrodialysis, for the same reason).

This figure summarises graphically the main highlights introduced in this short review. At this point, it is

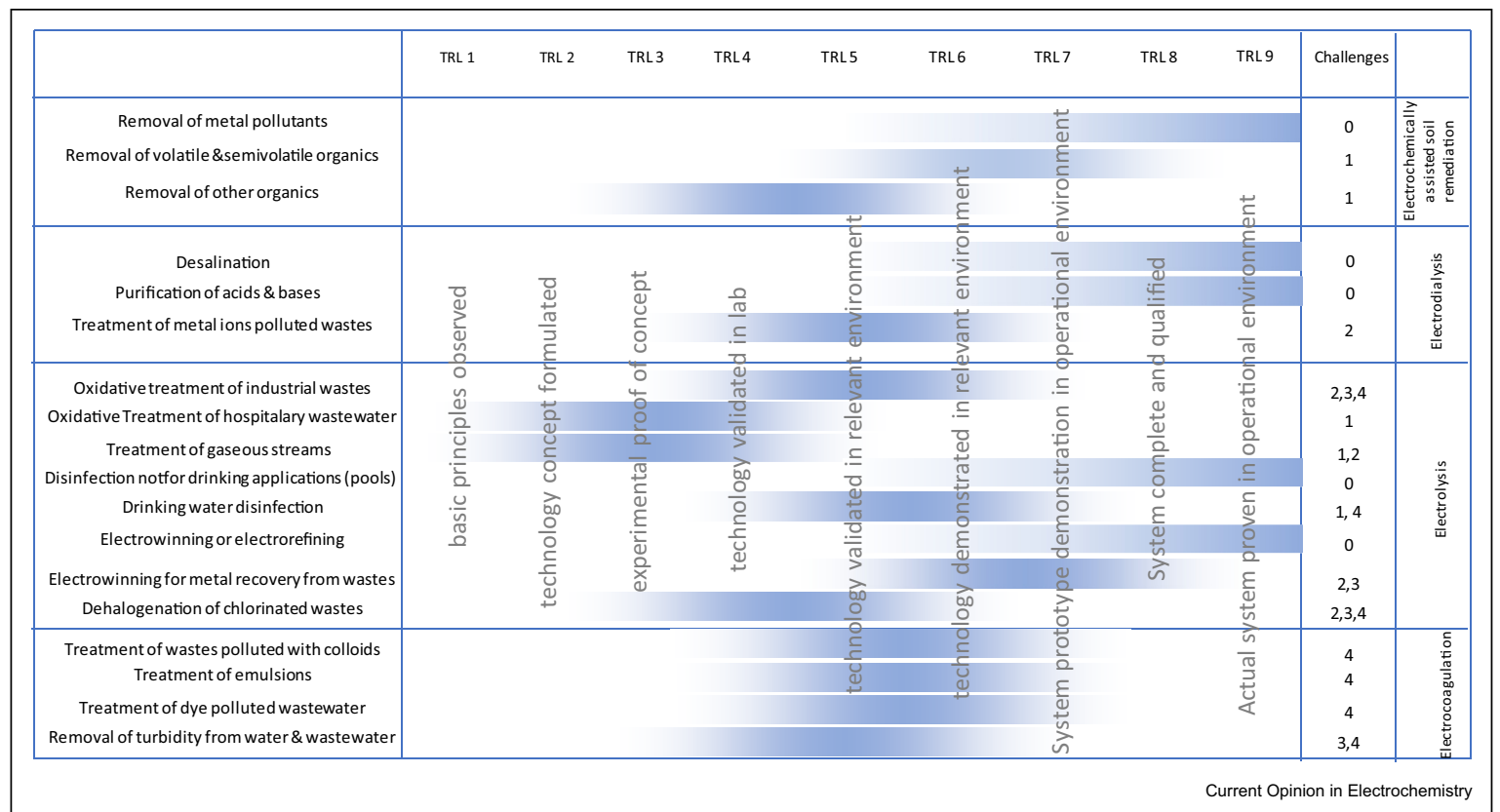

TRL of the main environmental electrochemical technologies, including the key challenges that have to be overpassed to increase this level: no significant challenges (0); further fundamental work (1); components development (membranes, electrodes, cells ...) (2); scale up (3); competition with efficient technologies (4). TRL, technology readiness level. 
important to note that increasing the TRL of a technology is a collaborative work not only including the work of base or technological scientists from academy but also the cooperation with small medium-sized enterprises (SME) and large enterprises (LE). Thus, all components of the value chain must be considered to get a successful implementation. The interest in each of these factors is complementary, and their appropriate combination must be considered as the major handicap to environmental electrochemical technology over the next few years.

\section{Conflict of interests}

The authors declare that they have no known competing financial interests or personal relationships that could have appeared to influence the work reported in this article.

\section{Acknowledgements}

Financial support from the Spanish Ministry of Economy, Industry and Competitiveness and the European Union through project CTM201676197-R and CTQ2017-91190-EXP (AEI/FEDER,UE) is gratefully acknowledged. The authors acknowledge funding support from Junta de Comunidades de Castilla-La Mancha (JCGM) and European Union (EU, FEDER) through the projects SBPLY/17/180501/000396 and SBPLY/17/ $180501 / 000330$.

\section{References}

Papers of particular interest, published within the period of review, have been highlighted as:

* of special interest

** of outstanding interest

1. Al Aukidy M, Verlicchi $P$, Voulvoulis $\mathrm{N}$ : A framework for the assessment of the environmental risk posed by pharmaceuticals originating from hospital effluents. Sci Total Environ 2014, 493:54-64.

2. Al-Qodah Z, Al-Shannag M, Bani-Melhem K, Assirey E, Yahya MA, Al-Shawabkeh A. Free radical-assisted electrocoagulation processes for wastewater treatment, vol. 16; 2018: 695-714.

3. Alshawabkeh AN, Yeung AT, Bricka MR: Practical aspects of insitu electrokinetic extraction. J Environ Eng-Asce 1999, 125: 27-35.

4. Barba S, Villaseñor J, Cañizares $P$, Rodrigo MA: Strategies for the electrobioremediation of oxyfluorfen polluted soils. Electrochimica Acta 2019, 297:137-144.

5. Barrera-Díaz C, Cañizares P, Fernández FJ, Natividad R, Rodrigo MA: Electrochemical advanced oxidation processes: An overview of the current applications to actual industrial effluents. J Mexican Chem Soc 2014, 58:256-275.

6. Bebelis S, Bouzek K, Cornell A, Ferreira MGS, Kelsall GH, Lapicque F, de Leon CP, Rodrigo MA, Walsh FC: Highlights during the development of electrochemical engineering. Chem Eng Res Design 2013, 91:1998-2020.

7. Brillas E, Martínez-Huitle CA: Decontamination of wastewaters containing synthetic organic dyes by electrochemical methods. An updated review. Appl Catal B: Environ 2015, 166-167:603-643.

8. Cameselle C, Gouveia S: Electrokinetic remediation for the $*$ removal of organic contaminants in soils. Curr Opin Electrochem 2018, 11:41-47.

The state-of-the-art of remediation of organic contaminants in soil with electrokinetic technology is discussed. Further researches are required for developing new and effective applications in contaminated soils and sediments.

9. Canizares P, Jimenez C, Martinez F, Rodrigo MA, Saez C: The $\mathrm{pH}$ as a key parameter in the choice between coagulation and electrocoagulation for the treatment of wastewaters. $J$ Hazardous Mater 2009, 163:158-164.

10. Choi J, Dorii P, Shon HK, Hong S: Applications of capacitive deionization: Desalination, softening, selective removal, and energy efficiency. Desalination 2019, 449:118-130.

11. Dai C, Zhou Y, Peng H, Huang S, Qin P, Zhang J, Yang Y, Luo L, Zhang X: Current progress in remediation of chlorinated volatile organic compounds: A review. J Indust Eng Chem 2018, 62:106-119.

12. De Battisti A, Formaglio P, Ferro S, Al Aukidy M, Verlicchi P: Electrochemical disinfection of groundwater for civil use - An example of an effective endogenous advanced oxidation process. Chemosphere 2018, 207:101-109.

13. Dewil R, Mantzavinos D, Poulios I, Rodrigo MA: New perspectives for Advanced Oxidation Processes. J Environ Manag 2017, 195:93-99.

This review analyses the actual knowledge of hybrid processes, heterogeneous semiconductor photocatalysis, sulphate-radical oxidation and electrochemical advanced oxidation for water/ wastewater treatment. The work ends with some perspectives that can be of interest for the ongoing and future research.

14. Ding J, Wei L, Huang $\mathrm{H}$, Zhao Q, Hou W, Kabutey FT, Yuan $Y$, Dionysiou DD: Tertiary treatment of landfill leachate by an integrated Electro-Oxidation/Electro-Coagulation/ElectroReduction process: Performance and mechanism. J Hazardous Mater 2018, 351:90-97.

15. Fakour H, Lo S-L: Formation of trihalomethanes as disinfection byproducts in herbal spa pools. Sci Rep 2018, 8. 57095709.

16. Feng $L$, van Hullebusch $E D$, Rodrigo MA, Esposito G, Oturan MA: Removal of residual anti-inflammatory and analgesic pharmaceuticals from aqueous systems by electrochemical advanced oxidation processes. A review. Chem Eng J 2013, 228:944-964.

17. Ganiyu SO, Vieira dos Santos E, Tossi de Araújo Costa EC, Martínez-Huitle CA: Electrochemical advanced oxidation processes (EAOPs) as alternative treatment techniques for carwash wastewater reclamation. Chemosphere 2018, 211: 998-1006.

18. Ganzenko O, Huguenot D, van Hullebusch ED, Esposito G, Oturan MA: Electrochemical advanced oxidation and biological processes for wastewater treatment: A review of the combined approaches. Environ Sci Pollut Res 2014, 21:8493-8524.

19. Garcia-Segura S, Eiband MMSG, de Melo JV, Martínez-

** Huitle CA: Electrocoagulation and advanced electrocoagulation processes: A general review about the fundamentals, emerging applications and its association with other technologies. J Electroanal Chem 2017, 801:267-299.

The importance of the operating parameters for efficient application of the electrocoagulation process as well as the combination of this electrochemical technology with electroanalysis techniques and other technologies are evaluated.

20. Gomes HI, Dias-Ferreira C, Ribeiro AB: Electrokinetic remediation of organochlorines in soil: Enhancement techniques and integration with other remediation technologies. Chemosphere 2012, 87:1077-1090.

This review systemizes useful information to researchers in organochlorines soil electroremediation. It concludes that a number of technical and environmental issues will require evaluation for full-scale application.

21. Hankin A, Bedoya-Lora FE, Ong CK, Alexander JC, Petter F, Kelsall GH: From millimetres to metres: the critical role of current density distributions in photo-electrochemical reactor design. Energy Environ Sci 2017, 10:346-360.

22. Isidro J, Brackemeyer D, Sáez C, Llanos J, Lobato J, Cañizares P, Matthee T, Rodrigo MA: Operating the CabECO® membrane electrolytic technology in continuous mode for 
the direct disinfection of highly fecal-polluted water. Sep Purif Technol 2019, 208:110-115.

23. Jeon TH, Koo MS, Kim H, Choi W: Dual-Functional Photocatalytic and Photoelectrocatalytic Systems for Energy- and Resource-Recovering Water Treatment. ACS Catal 2018, 8: $11542-11563$.

24. Lee SY, Gagnon GA: Review of the factors relevant to the design and operation of an electrocoagulation system for wastewater treatment. Environ Rev 2014, 22:421-429.

25. Lofrano G, Libralato G, Minetto D, De Gisi S, Todaro F, Conte B Calabrò D, Quatraro L, Notarnicola M: In situ remediation of contaminated marinesediment: an overview. Environ Sci Pollut Res 2017, 24:5189-5206.

26. Lopez-Vizcaino R, Risco C, Isidro J, Rodrigo S, Saez C, Canizares P, Navarro V, Rodrigo MA: Scale-up of the electrokinetic fence technology for the removal of pesticides. Part I: Some notes about the transport of inorganic species. Chemosphere 2017a, 166:540-548.

27. Lopez-Vizcaino R, Risco C, Isidro J, Rodrigo S, Saez C, Canizares P, Navarro V, Rodrigo MA: Scale-up of the electrokinetic fence technology for the removal of pesticides. Part II: Does size matter for removal of herbicides? Chemosphere 2017b, 166:549-555.

28. Lu L, Yazdi H, Jin S, Zuo Y, Fallgren PH, Ren ZJ: Enhanced bioremediation of hydrocarbon-contaminated soil using pilot-scale bioelectrochemical systems. J Hazardous Mater 2014, 274:8-15.

29. Luo T, Abdu S, Wessling M: Selectivity of ion exchange membranes: A review. J Membr Sci 2018, 555:429-454.

30. Marselli B, Garcia-Gomez J, Michaud PA, Rodrigo MA Comninellis $\mathrm{C}$ : Electrogeneration of hydroxyl radicals on boron-doped diamond electrodes. Journal of the Electrochem Soc 2003, 150:D79-D83.

This is the first manuscript reporting the role of hydroxyl radicals on electrolysis with diamond electrodes.

31. Martínez-Huitle CA, Rodrigo MA, Sirés I, Scialdone O: Single and * coupled electrochemical processes and reactors for the abatement of organic water pollutants: A critical review. Chem Rev 2015, 115:13362-13407.

The review is focused on the direct electrochemical oxidation, the indirect electrochemical oxidation mediated by electrogenerated active chlorine, and the coupling between anodic and cathodic processes. It is devoted to the critical assessment of the reactors that can be used to put these technologies into practice

32. Millán M, Rodrigo MA, Fernández-Marchante CM, Díaz-Abad S, Peláez MC, Cañizares P, Lobato J: Towards the sustainable powering of the electrocoagulation of wastewater through the use of a solar-vanadium redox flow battery: a first approach. Electrochim Acta 2018, 270:14-21.

This manuscript shows how the electrocoagulation process performs using renewable energy, Vanadium Redox flow batteries (VRFB) and energy from the grid. The results demonstrate that the use of VRFB as renewable energy storage system is a good option for this electrochemical technology.

33. Mook WT, Aroua MK, Issabayeva G: Prospective applications of renewable energy based electrochemical systems in wastewater treatment: A review. Renew Sustain Energy Rev 2014, 38:36-46.

This review mainly focuses on the application of electrochemical methods in water and wastewater treatment processes powered by solar energy based photovoltaic technology. The discussion provides an opportunity to expand the boundaries of conventional electrochemical system towards higher sustainability and reveals unlimited future prospects for multiple purposes.

34. Moreira FC, Boaventura RAR, Brillas E, Vilar VJP: Electrochemical advanced oxidation processes: $A$ review on their application to synthetic and real wastewaters. Appl Catal B: Environ 2017, 202:217-261.

This review describes the application of electrochemical advanced oxidation processes for the removal of persistent organic pollutants from synthetic and real wastewaters. The influence of the electrochemical reactor design and the main operational parameters is also reported.
35. Moussa DT, El-Naas MH, Nasser M, Al-Marri MJ:

A comprehensive review of electrocoagulation for water treatment: Potentials and challenges. J Environ Manag 2017, 186:24-41.

This work describes how to enhance electrocoagulation technology to increase its range of industrial scale applications.

36. Mukimin A, Zen N, Purwanto A, Wicaksono KA, Vistanty $H$, Alfauzi AS: Application of a full-scale electrocatalytic reactor as real batik printing wastewater treatment by indirect oxidation process. J Environ Chem Eng 2017, 5: $5222-5232$.

37. Munoz-Morales M, Saez C, Canizares P, Rodrigo MA: A new strategy for the electrolytic removal of organics based on adsorption onto granular activated carbon. Electrochem Commun 2018, 90:47-50.

38. Naje ASayc, Chelliapan Sskum, Zakaria Z, Ajeel MA, Alaba PA: A review of electrocoagulation technology for the treatment of textile wastewater. Rev Chem Eng 2017, 33:263-292.

39. Nidheesh PV, Zhou M, Oturan MA: An overview on the remova of synthetic dyes from water by electrochemical advanced oxidation processes. Chemosphere 2018, 197:210-227.

40. Perez JF, Llanos J, Saez C, Lopez C, Canizares P, Rodrigo MA The pressurised jet aerator: A new aeration system for highperformance $\mathrm{H} 2 \mathrm{O} 2$ electrolyzers. Electrochem Communications 2018, 89:19-22.

41. Pikaar I, Likosova EM, Freguia S, Keller J, Rabaey K, Yuan Z: Electrochemical abatement of hydrogen sulfide from waste streams. Crit Rev Environ Sci Technol 2015, 45:1555-1578.

42. Resch M, Bühler J, Schachler B, Kunert R, Meier A, Sumper A: Technical and economic comparison of grid supportive vanadium redox flow batteries for primary control reserve and community electricity storage in Germany. Int J Energy Res 2019, 43:337-357.

43. Rodrigo MA, Oturan N, Oturan MA: Electrochemically assisted remediation of pesticides in soils and water: a review. Chem Rev 2014, 114:8720-8745.

This is a critical review of pesticide removal from soils and water using electrochemical technologies. It concludes that considerable effort should also be devoted to scaling up electrochemical technologies to investigate important full-scale considerations such as cost and operation problems.

44. Sarkka H, Bhatnagar A, Sillanpaa M: Recent developments of * * electro-oxidation in water treatment - A review. J Electroanal Chem 2015, 754:46-56.

This review gives an overview of the use of electrochemical oxidation to treat effluents and to disinfect drinking water. It also gives an overview of the recent developments in electrode preparation and configurations.

45. Sirés I, Brillas E, Oturan MA, Rodrigo MA, Panizza M: Electrochemical advanced oxidation processes: today and tomorrow. A review. Environ Sci Pollut Res 2014.

This paper presents a general overview of the application of EAOPs on the removal of aqueous organic pollutants. A global perspective on the fundamentals and experimental setups is offered.

46. Souza FL, Llanos J, Sáez C, Lanza MRV, Rodrigo MA, Cañizares P: Performance of wind-powered soil electroremediation process for the removal of 2,4-D from soil. J Environ Manag 2016a, 171:128-132.

47. Souza FL, Saéz C, Llanos J, Lanza MRV, Cañizares P, Rodrigo MA: Solar-powered electrokinetic remediation for the treatment of soil polluted with the herbicide 2,4-D. Electrochimica Acta 2016b, 190:371-377.

48. Sun Y, Gao K, Zhang Y, Zou H: Remediation of persistent organic pollutant-contaminated soil using biosurfactantenhanced electrokinetics coupled with a zero-valent iron/ activated carbon permeable reactive barrier. Environ Sci Pollut Res 2017, 24:28142-28151.

49. Trellu $C$, Mousset $E$, Pechaud $Y$, Huguenot D, van Hullebusch ED, Esposito G, Oturan MA: Removal of hydrophobic organic pollutants from soil washing/flushing solutions: A critical review. J Hazardous Mater 2016, 306:149-174. 
50. Virkutyte J, Sillanpaa M, Latostenmaa P: Electrokinetic soil remediation - critical overview. Sci Total Environ 2002, 289: $97-121$.

51. Walsh FC, Arenas LF, Ponce de León C: Developments in electrode design: structure, decoration and applications of electrodes for electrochemical technology. J Chem Technol Biotechnol 2018, 93:3073-3090.

52. Walsh FC, Ponce de León C: Progress in electrochemical flow reactors for laboratory and pilot scale processing. Electrochimica Acta 2018, 280:121-148.
This work elucidates how to select the appropriate electrochemical flow reactor and types of electrode, depending on the laboratory or pilot scale application.

53. Wu S, Li H, Zhou $X$, Liang $P$, Zhang $X$, Jiang $Y$, Huang $X$ : A novel pilot-scale stacked microbial fuel cell for efficient electricity generation and wastewater treatment. Water Res 2016, 98: 396-403.

54. Zhou XL, Zhao TS, An L, Zeng YK, Wei L: Critical transport issues for improving the performance of aqueous redox flow batteries. J Power Sources 2017, 339:1-12. 